\title{
NÓS E OS OUTROS: CONCEPÇÕES DE PESSOA NO DEBATE SOBRE INFANTICÍDIO INDÍGENA NO CONGRESSO NACIONAL
}

MARLISE ROSA ${ }^{1}$

UFRJ

\begin{abstract}
RESUMO: Este ensaio deseja refletir sobre as concepções contrastantes de pessoa que, indiretamente, compõem o debate legislativo sobre o infanticídio indígena. Para os defensores da Lei Muwaji - como ficou conhecido o Projeto de Lei 1057/07, que propõe a criminalização do infanticídio indígena -, a noção de pessoa aparece como sinônimo da noção de vida, compreendida única e exclusivamente sob a ótica da sociedade ocidental. Assim, ao contrapor a noção ocidental-moderna de pessoa às diferentes noções ameríndias, além de apresentar as causas de interditos de vida, pretendo evidenciar a importância atribuída pelos povos indígenas ao nascimento social e à corporalidade como elementos constitutivos da pessoa. Não obstante, diante da insuficiência de dados sobre a ocorrência de casos de infanticídio indígena, sugiro pensá-lo como uma alegoria política e jurídica usada para legitimar a intervenção autoritária do Estado no cotidiano das aldeias, e assim justificar e reafirmar o poder tutelar que nunca foi totalmente sepultado.
\end{abstract}

PALAVRAS-CHAVE: Infanticídio indígena; Lei Muwaji; noção de pessoa.

ABSTRACT: This essay reflects upon the contrasting conceptions of personhood which pervade the legal debate surrounding indigenous infanticide. For the defenders of the Muwaji Law - as the Project of Law 1057/07 became known, which proposes the criminalization of indigenous infanticide - the concept of personhood appears as synonymous with the concept of life, understood solely and exclusively through the gaze of Western society. In this way, by contrasting Western notions of personhood with different Amerindian concepts, beyond presenting the causes of interruptions to life, I aim to demonstrate the importance attributed by indigenous peoples to social birth and corporeality as constitutive elements of personhood. Moreover, given the insufficiency of data regarding the occurrence of cases of indigenous infanticide, it is suggested that such cases are thought of as a political and judicial allegory, used to legitimize the authoritarian intervention of the state in the everyday lives of indigenous communities, and in this way to justify and reaffirm the judicial powers which were never entirely dissolved.

KEYWORDS: Indigenous infanticide; Muwaji Law; concept of personhood.

\footnotetext{
${ }^{1}$ Mestranda em Antropologia Social pelo Programa de Pós-Graduação em Antropologia Social do Museu Nacional/Universidade Federal do Rio de Janeiro (PPGAS/MN/UFRJ). Integra o Núcleo de Estudos do Poder/Curso de Pós-Graduação em Desenvolvimento, Agricultura e Sociedade/Universidade Federal Rural do Rio de Janeiro (NEP/CPDA/UFRRJ). E-mail: marlise.mrosa@ gmail.com .
}

Espaço Ameríndio, Porto Alegre, v. 8, n. 1, p. 163-193, jan./jun. 2014. 


\section{Introdução}

O debate sobre infanticídio indígena adentrou as portas do Congresso Nacional como resultado de uma atitude intervencionista de missionários no cotidiano das aldeias. Em julho de 2005, dois bebês da etnia Suruwahá, juntamente com suas mães, foram retirados de sua aldeia pela Jovens Com Uma Missão (JOCUM), missão evangélica estadunidense, presente entre esse povo desde a década de 1980. Essa ação teria sido motivada pelo fato de que ambas as crianças tiveram o status de pessoa negado por seu povo - Tititu, que nascera com indefinição sexual, e Iganani, com paralisia cerebral - e por conta disso, supostamente, estariam condenadas à morte. Muwaji, mãe de Iganani, a fim de salvar sua filha, teria se contraposto aos costumes de seu povo e optado por deixar a aldeia em busca de tratamento médico adequado.

$\mathrm{Na}$ ocasião, a saída de Tititu e de Iganani de sua aldeia suscitou uma polêmica de grande interesse midiático, e de grande repercussão e adesão civil, sobre a criminalização de práticas tradicionais que atentem contra a vida e a integridade físico-psíquica de crianças indígenas. Em decorrência disso, em 2006, a Frente Parlamentar Evangélica realizou uma Campanha Nacional a Favor da Vida e contra o Infanticídio; e em maio de 2007, juntamente com o lançamento oficial da Frente Parlamentar da Família e Apoio à Vida, o deputado Henrique Afonso, à época PT/AC, protocolou o Projeto de Lei 1057, que, em homenagem à mãe de Iganani, ficou conhecido como Lei Muwaji. Esse projeto de lei se propôs a legislar sobre aquilo que se convencionou chamar de infanticídio indígena, com o intuito de coibi-lo e penalizá-lo.

Para os parlamentares que são a favor da aprovação da Lei Muwaji, esta é uma campanha pró-vida. Contudo, para a Comissão de Assuntos Indígenas da Associação Brasileira de Antropologia (CAl/ABA), para o Conselho Indigenista Missionário (CIMI), como também para o movimento indígena, esse projeto de lei é uma tentativa de criminalização das coletividades indígenas, que traz implícita a suspeita de natural perversão e irracionalidade desse povo.

Nesse sentido, este ensaio contempla um dos aspectos que, 
indiretamente, é posto em xeque no debate legislativo sobre o infanticídio indígena: a noção de pessoa. O sentido indireto desse questionamento deve-se ao fato de que para os defensores da Lei Muwaji, a noção de pessoa aparece como sinônimo da noção de vida, e é abordada única e exclusivamente sob a ótica da sociedade ocidental. Desconsidera-se, assim, toda e qualquer possibilidade de se compreender, e ao mesmo tempo, de se lidar de forma diferenciada com tais categorias. O não dito por trás desse debate é que não estamos falando de tirar a vida, mas sim do que é a vida em um sentido mais amplo, que comporta diferentes visões de mundo.

Nas sociedades ocidentais, conforme propõe DaMatta (1997), o indivíduo é a categoria dominante do discurso filosófico, jurídico, político, social, econômico e religioso, e essa categoria, quando projetada para fora do sistema ocidental, é utilizada, equivocadamente, para expressar realidades em que sua existência é nula. Frente a isso, a fim de tentar lançar luz sobre o paradoxo que se instaura diante do debate sobre a criminalização do infanticídio indígena, este ensaio foi organizado contemplando três temáticas que se entrelaçam e se contrapõem ao mesmo tempo: a noção ocidental-moderna de pessoa; as diferentes noções ameríndias de pessoa; e as causas de interdito de vida.

Dedico grande atenção à descrição das diferentes noções ameríndias de pessoa, sob o intuito de assim demonstrar os moldes através dos quais se inscrevem outras racionalidades. A ideia é, através do contraste, evidenciar que para os povos indígenas, nessa literatura, o marco para existência de pessoa, ao contrário da concepção ocidental, relacionada com o nascimento biológico, é ao nascimento social e a corporalidade como elementos constitutivos da pessoa, de acordo com o nascimento biológico. É o estabelecimento de relações adequadas, a inserção em uma rede de parentesco, e os rituais de iniciação e de passagem, que conformam, então, o nascimento social. De modo geral, é esse espaço de tempo entre o nascimento biológico e o nascimento social que comporta as causas de interdito de vida. Portanto, se para as sociedades indígenas a vida se inicia mediante um consentimento social, não faz sentido a acusação de tirar a vida, quando esta nem mesmo socialmente existe. Trata-se, na verdade, de prescrições sociais que 
julgam um indivíduo (no sentido empírico do termo) apto ou não a tornar-se pessoa, ou seja, a nascer socialmente.

Vale lembrar, entretanto, que diferentes noções de pessoas entre os indígenas não obrigatoriamente implicam na interdição da vida. Essa prática pode ser engendrada também por outros fatores, como controle demográfico e/ou emergência de guerras, por exemplo. Aqui me detenho especificamente na relação entre noção de pessoa e interdito de vida, por este ser, em minha opinião, um dos principais elementos intrigantes desse debate, que, em sua essência, se assemelha ao debate em torno da legalização do aborto, por questionar o que é vida e onde esta começa.

A Lei Muwaji e as posições que a sustentam têm como foco a negação da racionalidade dos indígenas, reduzindo-os aos estereótipos; diante disso, pretendo, ao contrapor a noção ocidental-moderna de pessoa às diferentes noções ameríndias de personitude ${ }^{2}$, demonstrar a existência de uma racionalidade própria que rege e fundamenta suas práticas. Essa abordagem não tem a pretensão de solucionar o problema que envolve o debate sobre infanticídio indígena no cenário político atual, muito menos reduz as causas de interditos de vida entre os indígenas exclusivamente à atribuição do status de pessoa. Trata-se apenas de uma tentativa de demonstrar a existência de dois campos de racionalidade - ocidental e indígena - que operam com categorias distintas.

\section{A noção de pessoa ocidental-moderna: o indivíduo}

Mauss (2003), em seu clássico ensaio Uma categoria do espírito humano: a noção de pessoa, a noção do "eu", como o próprio título sugere, tenta reconstruir a história social dessas categorias do espírito humano, demonstrando assim que tal ideia, embora nos pareça inata, foi lentamente e diferentemente elaborada pelas sociedades com base em suas religiões, costumes e estruturas sociais. O autor descreve o processo de formação da noção moderna/ocidental de pessoa. Esse processo inicia-se com a identificação, entre algumas sociedades

\footnotetext{
${ }^{2}$ Termo utilizado como tradução da expressão em inglês personhood.
} 
tribais, da noção de personagem, do papel desempenhado pelo indivíduo tanto nos dramas sagrados, como também na vida familiar. A noção de persona latina, oriunda das máscaras rituais, teve início com a civilização latina. Com os romanos, a pessoa se tornou um fato fundamental do direito, isto é, um sujeito portador de direitos; ao mesmo tempo, a persona se tornou o sinônimo da verdadeira natureza do indivíduo. Com isso, os filhos adquiriram persona, resultando no fim do pátrio poder. Posteriormente, sob influência da filosofia estoica, soma-se ao sentido jurídico de pessoa o sentido moral do ser consciente, autônomo, livre. Com o advento do cristianismo, a noção de pessoa recebeu a sua base metafísica - o caráter individual em relação a Deus. E é no final do século XVIII, sob influência de filósofos como Kant e Fichte, que a noção de pessoa tornou-se a categoria do eu (indivíduo), condição da consciência e da ciência (MAUSS, 2003).

A noção de pessoa própria das sociedades ocidentais modernas é, portanto, o indivíduo, que encontra em Dumont (1992a e 1992b), seu principal expoente analítico. Entretanto, a exemplo do que sugere o autor, antes de adentrarmos essa emblemática seara do individualismo, é preciso esclarecer que por indivíduo nos remetemos tanto ao sujeito empírico, o exemplar individual da espécie humana, como também a um valor, um ser moral não social que representa a ideologia moderna do homem e da sociedade. Sob essa perspectiva, Dumont propõe a existência de duas espécies de sociedades, em que "no caso que o indivíduo é o valor supremo, falarei de individualismo; nos casos opostos, em que o valor é a sociedade como um todo, falarei de holismo" (DUMONT, 1992a, p. 35).

Nas sociedades tradicionais/holísticas:

[...] o acento incide sobre a sociedade em seu conjunto, como Homem coletivo; o ideal define-se pela organização da sociedade em vista de seus fins (e não em vista da felicidade individual); trata-se, antes de tudo, de ordem, de hierarquia, cada homem particular deve contribuir em seu lugar para a ordem global, e a justiça consiste em proporcionar as funções sociais com relação ao conjunto (DUMONT, 1992b, p. 57).

Enquanto que nas sociedades modernas, por sua vez, ocorre exatamente o contrário. $\mathrm{O}$ homem constitui-se como elemento central, 
e sobrepõe-se à sociedade. "Ontologicamente a sociedade não existe mais, ela é apenas um dado irredutível ao qual se pode em nada contrariar as exigências de liberdade e igualdade" (DUMONT, 1992b, p. 57).

Frente a isso, o problema, para Dumont (1992a), reside em compreender como, a partir do tipo geral das sociedades holísticas, se desenvolveu o individualismo moderno. Ao citar a figura do renunciante indiano, ou seja, um "indivíduo-fora-do-mundo", o autor lança a hipótese de que o individualismo, quando aparece em uma sociedade do tipo tradicional, holística, será em oposição a ela, e ao mesmo tempo, servindo-Ihe como suplemento. Assim, ao realizar uma minuciosa investigação que percorre a filosofia antiga e a história do cristianismo até chegar a Calvino, o autor detecta que esse "indivíduofora-do-mundo" também está presente no cristianismo. Portanto, Dumont (1992a) sugere que, no Ocidente, a ideia de indivíduo tenha surgido com o cristianismo, quando, através dos ensinamentos de Cristo, e em seguida de Paulo, o homem passou a ser visto como um "indivíduo-em-relação-com-Deus", isto é, um indivíduo essencialmente fora do mundo. Seria por meio dessa relação filial com Deus que a alma teria adquirido um caráter individual, igual e universal. Surgira, então, o que o autor identifica como um individualismo extramundano, alicerçado no dualismo entre a obediência aos poderes deste mundo e a revelação divina. Esse antagonismo mundano teria sido superado apenas com a teocracia de Calvino, que transformou o "indivíduo-forado-mundo" em "indivíduo-no-mundo", permitindo ao individualismo reinar sem restrições ou limitações.

Faz-se necessário destacar, entretanto, que é apenas na civilização ocidental "que a ideia de indivíduo foi apropriada ideologicamente, sendo construída a ideologia do indivíduo como centro e foco do universo social, contendo dentro de si a sociedade [...]" (DAMATTA, 1997, p. 221). Ainda assim, é pertinente dizer que embora a noção ocidental-moderna de pessoa predominante seja o indivíduo, essa não é a única. É preciso considerar o nosso outro, ou seja, os grupos orientados por uma perspectiva tradicional/holística, como é o caso das sociedades ameríndias, que dispõem de diferentes concepções de personitude - elemento que, por sua vez, compõe uma das 
dimensões do debate em torno do infanticídio indígena. Ou mais precisamente, conforme destaca DaMatta (1997), as noções de pessoa e indivíduo coexistem dialeticamente no interior de uma mesma sociedade, concebendo o universo social e delimitando as formas de agir nele.

Essa análise de DaMatta, portanto, pode ser usada para exemplificar a tese dumontiana de que uma sociedade tal como concebida pelo individualismo, na realidade nunca existiu, uma vez que o indivíduo vive de ideias sociais. Conklin e Morgan (1996) compartilham desse pressuposto ao afirmarem que as ideologias de personitude raramente são compartilhadas uniformemente por todos os membros de uma sociedade. Tais ideologias são contestadas e construídas de diferentes formas dentro dos limites de uma mesma sociedade.

Todavia, para além dos aspectos filosóficos e morais da noção ocidental/moderna de pessoa, gostaria de lançar luz sobre a imagem de corpo por ela acionada. De acordo com Conklin e Morgan (1996), a concepção ocidental do corpo o compreende estritamente em termos biológicos, assim regido e controlado por processos tidos como naturais. Ao contrário das ideologias não ocidentais, as interações sociais não impactam na criação e manutenção do corpo físico - o social é reconhecido sobre o corpo, porém, não no corpo, como construção material. Dessa forma, o reconhecimento do status de pessoa também se atrela a essa concepção biológica, alicerçada na capacidade do corpo individual desempenhar funções específicas. Frente a isso, as autoras asseveram que "quando a personitude é entendida como sendo atribuída por fatores não sociais, ela não pode ser facilmente anulada, atenuada ou truncada por ação social" (CONKLIN e MORGAN, 1996, p. 662), ou seja, "pessoas ocidentais, uma vez estabelecidas, não são facilmente desfeitas" (CONKLIN e MORGAN, 1996, p. 662). Em contraste, as sociedades ameríndias não compreendem a pessoa/corpo como constituída mediante o nascimento biológico. Tais cosmologias, de modo geral, entendem a personitude como uma qualidade processual que é adquirida gradualmente por meio das interações sociais, em que o corpo não se faz pronto com o nascimento biológico, mas sim é criado ao longo do ciclo da vida por meio de diferentes processos de 
transformação social.

\section{Diferentes noções ameríndias de pessoa}

Entre as sociedades ameríndias, nos deparamos com diferentes noções e construções da personitude. Porém, de modo geral, conforme afirmam Seeger, DaMatta e Viveiros de Castro (1979), a elaboração da noção de pessoa encontra na referência à corporalidade seu principal idioma simbólico.

A produção física de indivíduos se insere em um contexto voltado para a produção social de pessoas, membros de uma sociedade específica. O corpo tal como nós ocidentais o definimos, não é o único objeto (e instrumento) de incidência da sociedade sobre os indivíduos: os complexos de nominação, os grupos e identidades cerimoniais, as teorias sobre alma, associam-se na construção do ser humano tal como entendido pelos diferentes grupos tribais. Ele, o corpo, afirmado ou negado, pintado e perfurado, resguardado ou devorado, tende sempre a ocupar uma posição central na visão que as sociedades indígenas têm da natureza do ser humano (SEEGER, DAMATTA e VIVEIROS DE CASTRO, 1979, p. 4).

O corpo, entretanto, ao contrário dos preceitos ocidentais, não é dado no momento do nascimento biológico. Ele é criado ao longo do ciclo da vida por meio de diferentes processos de transformação social. Ao mesmo tempo, conforme asseveram os autores, o corpo não é o único instrumento para a definição da personitude, somados a ele incidem outros elementos constitutivos, como as práticas de nominação, relações de parentesco, relações sociais e representações sobre a alma. São exatamente alguns desses processos que pretendo, através de relatos etnográficos, demonstrar aqui.

Entre os Bororo, Viertler (1979) destaca que associadas à noção de pessoa humana estão as ideias de trabalho, respeito e integridade. Como elementos constitutivos da pessoa, a autora identifica as interpretações sobre a força vital, o nome, o sopro e a alma-sombra, o nome de estojo peniano, os apelidos, os nomes civilizados, os nomes de 
caça em nome de finados e a crença no herói mítico, ledaga.

A interpretação acerca da força vital decorre da crença bororo de que, tanto a vida animal como também humana, é gerada por um tipo de força vital associada a algumas expressões materiais dotadas de cheiro forte, como sangue menstrual e sêmen. A entidade sobrenatural, o bope, é responsável pela formação do feto e também pelo declínio da força vital dos indivíduos, tornando-os velhos e doentes, ou causandoIhes a morte.

A cerimônia de nominação, por sua vez, corresponde ao momento de formação da pessoa enquanto ser social. "O nome pessoal dado à criança vai integrá-la na sociedade dos nominados" (VIERTLER, 1979, p. 23), tirando-a do anonimato. Nesta ocasião, a criança se constitui enquanto personalidade social, e tem determinado seu papel na comunidade.

Por sopro e alma-sombra, de acordo com a autora, compreendese a relação entre a atribuição dos nomes pessoais e dos enfeites a eles associados com o sopro na cabeça da criança e a uma alma-sombra de alguém morto há muito tempo. O sopro se encontra enclausurado em uma cabaça mortuária, último reduto de um funeral. O nome e a almasombra mantêm-se integrados enquanto houver força vital no corpo do Bororo, sendo a desintegração provocada por feitiços que manipulam vegetais que as almas comem.

Outro elemento constitutivo da pessoa entre os Bororo é a outorgação do nome de um estojo peniano, que ocorre no auge da força física dos jovens de sexo masculino por um padrinho do outro lado, autorizando-os a procriar a partir de então. Esse momento corresponde à instituição de um novo conjunto de direitos e deveres, "[...] constitui uma afirmação do indivíduo enquanto homem e o início de um longo processo de aprendizado dos mistérios associados a vida cerimonial [...]" (VIERTLER, 1979, p. 26).

Enquanto isso, o processo de atribuição de apelidos jocosos que destacam algum aspecto grotesco da pessoa visam ressaltar, de forma caricatural, características que não correspondem à medida certa. Da mesma forma, a atribuição de nomes de civilizados, como, por exemplo, "Eduardos, Eduardões e Eduardinhos", elucida a existência de laços sociais entre tais pessoas. Já o momento de atribuição de um nome de 
caça de morte, deve-se ao fato de que, após a morte de um Bororo, seu nome pessoal, apelido, nome de estojo peniano e nome de civilizados não são mais pronunciados, sendo substituídos pelo nome de caça. Isso ocorre em virtude da crença de que a morte faz com que a força vital fuja da alma-sombra do corpo falecido para algum animal. Por fim, é a crença no herói mítico ledaga, e seu conhecimento sobre as técnicas mortuárias, decorações e pinturas corporais, que orienta a organização dos rituais funerários (VIETLER, 1979).

Percebemos, portanto, que entre os Bororo a elaboração da personitude e a definição dos papéis sociais a serem desempenhados não é definida no momento de nascimento biológico, mas sim se dá gradativamente ao longo do ciclo de vida do indivíduo.

Outro estudo ilustrativo das diferentes noções ameríndias de pessoa foi realizado por Florencia Tola (2007), junto aos Toba (Qom) do Chaco argentino. A fim de melhor retratar a cosmologia dos Qom, a autora lança mão dos conceitos de "pessoa corporizada" e "extensões corporais" para explicar como corpo e pessoa são concebidos e vividos por esse povo. "Os Oom concebem a pessoa como extensa, na medida em que seu corpo não representa uma fronteira entre os seres existentes nem tampouco uma barreira que encerraria os elementos que a constituem" (TOLA, 2007, p. 502). O conceito de pessoa corporizada refere-se à pessoa humana e permite, portanto, considerar as estreitas relações existentes entre pessoa e os processos coletivos de constituição corporal, uma vez que a pessoa se "torna corpo" por meio das ações e intenções de outrem.

Por extensões corporais a autora faz referência a alguns componentes da pessoa, que mesmo fora do limite corporal ainda são concebidos como a pessoa. Tais extensões correspondem aos fluidos corporais (sangue e esperma) e também o lqui'i (alma que anima o corpo), o calor corporal e o nome.

Após a concepção, a troca de fluidos corporais entre os pais ao longo da gestação tem a finalidade de formar e transformar o corpo da criança, mas é durante os quatro primeiros meses que o embrião recebe seu lqui'i e sua imagem corporal. Entretanto, a autora destaca que a ideia de concepção não se funda apenas na combinação dos fluidos corporais. Soma-se a isso a intervenção de um elemento não humano, 
que deposita o Iqui'i da criança no ventre da mulher. O lqui'i, antes de descer ao ventre feminino e transformar-se em corpo, vive no céu na forma de ente, representando assim a pessoa em potencial. Essa condição demonstra, portanto, que a existência humana, entre os Toba, não se limita exclusivamente ao corpo.

O lqui'i ao mesmo tempo é um elemento constitutivo de humanos e não humanos (espíritos xamânicos, mortos, mestres das espécies, etc.), proporcionando-Ihes capacidade reflexiva, intencionalidade, comunicação e percepção visual. Uma das formas de estabelecer a distinção entre humanos e não humanos se dá por meio do calor corporal, que para o Qom "[...] é um atributo corporal sem o qual uma pessoa não seria totalmente humana. Sua ausência define a diferença entre um corpo vivo e outro morto, assim, entre os humanos e nãohumanos privados de corpo" (TOLA, 2007, p. 510). Portanto, o calor humano é uma característica essencialmente dos seres vivos, que se define pela oposição aos corpos dos mortos.

A atribuição de nome, por sua vez, explicita o reconhecimento público e coletivo do elo social que une o indivíduo ao seu grupo de parentesco. Além do nome pessoal atribuído pelos pais, os Qom também recebem um nome coletivo, e, atualmente, a utilização de apelidos entre os jovens é altamente difundida (TOLA, 2007).

Deste modo, Tola (2007) demonstra que, entre os Qom, o conceito de extensões corporais evidencia que a noção de pessoa não se limita apenas ao corpo. O corpo é a dimensão onde se dá o devir da pessoa, ao mesmo tempo, é nele que se inscrevem a diferença e a continuidade entre os entes.

Entre os Wari', de Rondônia, conforme demonstram Conklin e Morgan (1996), o corpo e a troca de fluidos corporais entre os indivíduos têm importância semelhante à atribuída pelos Qom. Para os Wari', a personitude não é compreendida como uma condição fixa, mas sim como um processo interativo que ocorre gradualmente, e pode ser perdida e atenuada sob determinadas condições associadas a alterações na interação social e na composição corporal. O social e o biológico são tomados como fenômenos interdependentes, isso porque 0 compartilhamento das substâncias corporais (principalmente o sangue e os fluidos análogos) define os laços entre os membros de uma união 
conjugal, da família nuclear, das redes de parentesco, de forma que as identidades sociais são fisiologicamente definidas.

O feto é formado pela união do sangue materno (que forma o sangue fetal) com o sêmen paterno (que forma o corpo fetal), e assim representa a união de seus genitores, e entre seu grupo de parentesco. Em decorrência da crença de que o sêmen do pai constrói o corpo do feto, os Wari' recomendam aos casais que mantenham relações sexuais durante a gravidez, do contrário, o feto estará em perigo. Diante disso, o bebê wari' pode ter vários pais, pois qualquer homem que tenha feito sexo com uma mulher grávida contribui com sêmen para a formação do corpo do feto, e pode reivindicar a paternidade biológica. Isso significa que a gravidez entre os Wari' é um processo social que envolve múltiplas contribuições de nutrição, com pelo menos dois indivíduos ligados a duas diferentes redes de parentesco, o que evidencia, portanto, que o corpo é uma criação social (CONKLIN e MORGAN, 1996).

Após o nascimento, a mãe, através da amamentação, continua o processo de transferência de sangue para a criança, enquanto que ao pai cabe fornecer alimentos para a mãe e ao recém-nascido, como continuidade do processo antes realizado por meio do sêmen. A atribuição do nome ao bebê ocorre apenas após seis semanas de seu nascimento, quando sai do período de reclusão e passa a interagir com a comunidade. O crescimento, amadurecimento e aquisição plena da personitude ocorrem simultaneamente ao processo de constituição de relações sociais independentes e desenvolvimento da sua composição corporal própria - sangue e substâncias corporais. Essa trajetória de desenvolvimento, cada vez mais independente física e socialmente, culmina com a puberdade. Para as meninas esse momento consolida-se com o primeiro intercurso sexual, quando, através do sêmen masculino, o sangue feminino sofre transformações e a mulher passa a menstruar. Já para os rapazes, até 1960 esse momento era marcado por um ritual seguido do assassinato de um inimigo não Wari' - posteriormente a essa data, quando tal ritual foi abandonado, o processo masculino de transição para a idade adulta não é precisamente conhecido. Assim, Conklin e Morgan (1996) demonstram que a personitude wari' é adquirida gradualmente através da interação do indivíduo com outras pessoas e incorporação de seus fluidos corporais, atribuindo, portanto, 
ao social e ao biológico igual importância.

Entre os Kaxinawá, por sua vez, nos deparamos com uma noção de pessoa estreitamente relacionada às teorias sobre as almas. McCallum (1996) aponta a importância das concepções na existência de duas almas principais, a alma do olho, chamada de verdadeira alma, yuxin kuin, visível através do brilho do olho; e a alma do corpo, yuda yuxin. A alma do corpo está ligada à sombra da pessoa. "[...] Vincula-se intimamente ao corpo e, quando o deixa, causa doenças graves e até a morte" (MCCALLUM, 1996, p. 55). A alma do corpo, para os Kaxinawá, constitui-se por meio da intervenção humana no corpo, enquanto que a alma do olho está associada à alma imortal criada por Deus.

Após a morte, o velório tem a finalidade tanto de acalmar a alma do corpo como também de assegurar seu desligamento do corpo. Em decorrência do perigo que as almas dos mortos representam tanto para os moradores do local como também para os parentes mais próximos, uma das formas de assegurar a separação entre alma e corpo é destruir os pertences da pessoa falecida. Outro meio utilizado até aproximadamente a década de 1950, era o endocanibalismo. "Consumindo a carne, os parentes podiam talvez reter em si mesmos alguma coisa do morto, liberando sua alma para voar em direção à floresta" (MCCALLUM, 1996, p. 70). A primeira parte do ritual funerário, o festim da carne (ferver, esfriar e consumir a carne humana), lidava com a alma do corpo, e a segunda parte, o festim dos ossos (assar, moer e consumir os ossos), lidava com a alma do olho.

A noção de pessoa entre os Kaxinawá, portanto, está interrelacionada com a crença na existência de duas almas principais - a do olho e a do corpo - e com as transformações que ocorrem com o corpo. Nesse sentido:

O gênero deve ser entendido como um aspecto da humanidade que se constrói ao longo da infância e da vida adulta. [...] O gênero não é adscrito a priori, como decorrência do sexo biológico; ao contrário, vai sendo inscrito no corpo no decorrer do processo de transformação das crianças em verdadeiros seres humanos (MCCALLUM, 1996, p. 53).

Esse princípio assemelha-se ao pensamento yawalapíti, como 
relata Viveiros de Castro (1979). Para esse povo, o corpo humano necessita ser submetido a processos intencionais e periódicos de fabricação. É por meio dessas transformações corporais que se constitui a identidade social. O social, portanto, cria o corpo, "dessa forma, a natureza humana é literalmente fabricada, modelada, pela cultura" (VIVEIROS DE CASTRO, 1979, p. 41).

O processo de construção da pessoa xinguana, de acordo com o autor, ocorre por meio do complexo de reclusão, que inclui a couvade, a puberdade, a doença, a iniciação xamanística, o luto, a gestação e o sepultamento. Toda reclusão é compreendida pelos Yawalapíti como uma mudança substantiva do corpo. É através do complexo de reclusão que os papéis sociais são assumidos.

Durante os complexos de reclusão, algumas substâncias são manipuladas, que, devendo entrar ou então sair do corpo, colaboram para seu crescimento e fortalecimento. Entretanto, a lógica de incorporação/exportação de substâncias críticas ocorre durante toda a vida da pessoa xinguana, sendo acentuada nos momentos de reclusão. Isso denota que o que se passa com o corpo xinguano, tanto interior quanto exteriormente, é de interesse da sociedade (VIVEIROS DE CASTRO, 1979).

Já entre os Krahó, Carneiro da Cunha (1978) demonstra que a noção de pessoa é constituída nas relações sociais, e tem como modeladores a amizade formal e o companheirismo. A primeira é pautada no contraste absoluto. $\mathrm{O}$ amigo formal é o outro, o antônimo, a negação, portanto, delimitaria os limites. O segundo, como o próprio substantivo sugere, implica em uma relação de identificação, de simultaneidade e similaridade de ação, ou seja, aquele que acompanha as ações cotidianas de outrem. É por meio da ideia de companheiro que o Krahó se reconhece e se assume enquanto homem agindo.

A relação imperante com o amigo formal é de respeito e evitação. Ele é por excelência um estranho, um não parente. Ao mesmo tempo, além da relação de evitação, pode-se manter com o amigo formal uma parceria jocosa, uma vez que, "[...] ao insultar, ele ao mesmo tempo reafirma sua estranheza e a inversão que seu gracejo implica" (CARNEIRO DA CUNHA, 1979, p. 34).

Deste modo, Carneiro da Cunha (1978 e 1979) evidencia que o 
processo de constituição da pessoa entre os Krahó é diretamente dependente das relações sociais, em que se destaca a oposição (amizade formal) por um lado, e a semelhança (companheirismo) por outro. A pessoa se instaura, então, por meio da intersecção de ambas.

Entre os Piro da Amazônia peruana, Minna Opas (2005) também retrata a importância do corpo na constituição da noção de pessoa. A cosmologia desse povo comporta a noção de pessoa humana e não humana, e é por meio do corpo que ocorre esse processo de mutação. A noção de pessoa humana está estreitamente vinculada à ideia de moralidade, enquanto que a concepção de pessoa não humana fica reclusa à imoralidade. Como moralidade, os Piro compreendem a troca de alimento, a convivência com os parentes e a manutenção de relações sexuais legítimas.

Os Piro acreditam que, em decorrência da interação corporal, o recém-nascido está conectado ao pai e à mãe; assim, qualquer má conduta por parte dos pais pode prejudicar a criança ou causar-lhe alterações físicas. Por exemplo, a alma de um animal morto pelo pai, em busca de vingança, poderia causar alterações físicas na criança. Isso se deve ao fato de que, durante os primeiros meses de vida, o corpo da criança encontra-se em um estado instável e subdesenvolvido. Para crescer e se tornar uma pessoa humana, o bebê deve interagir socialmente e ser bem alimentado com alimentos apropriados fornecidos pelos parentes, o que estabelece e ao mesmo tempo reforça as redes de cuidado, amor e respeito.

A autora ressalta, entretanto, que, de acordo com a cosmologia piro, ninguém se torna totalmente humano. A única forma de alcançar certa estabilidade é viver perto de seus parentes e consolidar uma existência compartilhada com os humanos adequados. A necessidade de viver coletivamente justifica-se pelo fato de que na presença de outros humanos, seres não humanos (mortos, animais, espíritos) não se aproximam. Portanto, ao estabelecer uma relação humano a humano, automaticamente se exclui uma relação de humano para com não humano. Porém, embora tanto os seres humanos como também os seres não humanos sejam considerados pessoa, a relação humano para com um não humano causa loucura, definhamento e a morte, comprovando a incompatibilidade entre ambos. 
Já entre os Jodï, grupo indígena da Guayana venezuelana, Eglée Lopez (2006) demonstra que a noção de pessoa está diretamente relacionada ao mito do $\mathrm{sol}^{3}$ enquanto criador da humanidade:

Quando iyëka ja [homem inclemente, pícaro primordial] comeu a humanidade, jtinewa [o sol, homem muito grande] deteve seu caminho ao meio-dia até que ñamulie jaiñe [primeiro filho homem] subiu e o matou. ñamulie jaiñe gritou quando se fez a escuridão. Seus pais e seu irmão mais novo na terra não anunciaram a morte do sol. jtinewa renasceu pequenino do ijkwo jo [coração] do primeiro sol, mas cresceu rapidamente enquanto ñamulie jaiñe mostrava-Ihe seu caminho. ñamulie jaiñe desceu à terra e se foi ao bosque com jtujtea [irmão mais novo, homem]. uli yewi [tigre grande, predador por excelência], ao vê-los, comeu ñamulie jaiñe. Por três dias, este voltou, ao crepúsculo, e pediu a seus pais e a seu irmão que the abrissem a porta. Sequer falaram com ele. Triste, à meia-noite do terceiro dia, ñamulie jaiñe despediu-se, dizendo-lhes: perderam a oportunidade de ser jluweoaï [eternamente jovens], morrerão e deverão seguir o caminho dos mortos, que hoje abrirei pela primeira vez. Partiu de onde sai o sol (mameka, rio acima, em jwaleu inëbo, montanha sagrada), até onde ele se oculta [chaka, rio abaixo] (LOPEZ, 2006, p. 361).

É por meio do mito do sol que os Jodï explicam, de forma conectada e sobreposta, as noções de pessoa, predação e eternidade. No que concerne especificamente à noção de pessoa, o mito do sol alude a três componentes, "[...] ijkwo ju [lit. coração, vida], ïnë ja dodo [lit. envoltório de carne animado, corpo palpável] e jnamodi [lit. espírito, ânimo], definidos em etapas da vida: nascimento, adolescência e morte" (LOPEZ, 2006, p. 362).

Na cosmovisão jodï, Lopez (2006) afirma que o devir cotidiano é concatenado a eventos ocorridos em tempos mitológicos. Assim, os costumes e regras referentes à gravidez, ao parto e ao período pósparto são compreendidos como ensinamentos de jkajo ja (homem sábio e imortal, que repovoou a terra com homens), repassados à primeira mulher, que nasce do tronco da jtijtïmö jyeï (árvore sonora). Entretanto,

\footnotetext{
${ }^{3} \mathrm{O}$ sol, na cosmologia jodi, é compreendido como pessoa por excelência. Ele "[...] interage com entes de todas as esferas espaciais (céu, terra, submundo e o rio que corre abaixo deste) e cuja rota está abarrotada de seres e espaços concretos" (LOPEZ, 2006, p. 368).
}

Espaço Ameríndio, Porto Alegre, v. 8, n. 1, p. 163-193, jan./jun. 2014. 
do mesmo modo como entre outros povos ameríndios, a consolidação da pessoa não acontece concomitante ao momento do nascimento biológico, mas sim com um rito de passagem e iniciação que ocorre na adolescência, após a primeira menstruação, na mulher, e no homem, quando se observam os primeiros sinais corporais de puberdade. $\mathrm{O}$ rito, igualmente aos costumes referentes à couvade, é orientado em conformidade com a narrativa mitológica. É somente após a perfuração do septo nasal, realizada ao fim de muitos dias de isolamento, que o iniciado torna-se completamente humano.

A morte corresponde à última parte do mito, e informa sobre a condição mortal humana. Ela é resultado do silêncio, no mito, frente à morte do sol. Ao morrer, cada ser humano percorre a rota do sol, e os três componentes da pessoa - coração, corpo e jnamodï - sofrem transformações complexas, inspiradas nas transformações sofridas pelo sol, narradas no mito. Após o cumprimento dos ritos funerários por seus parentes, o morto que tiver o nariz perfurado e o pedaço de madeira inserido no orifício, e também tiver o hábito de consumir tabaco, sobreviverá eternamente; do contrário, estará condenado à extinção total, sendo devorado por jlojlkoi uli ja - pessoa predadora enorme, hipóstase da lagartixa (LOPEZ, 2006).

A cosmologia jodï comporta uma lógica cíclica de constante transformação entre os seres de materialidades diversas, o que, de acordo com a autora, torna difícil a ideia de discricionariedade. Constata-se, portanto, que o status de sujeito não está circunscrito ao homem exclusivamente, mas a diversos seres e objetos relacionais e situacionais a que se atribuem racionalidade, autonomia, intencionalidade e sensibilidade. Nesse sentido, a corporalidade humana constitui-se como o eixo organizador central, em que o Jodï, ao agir como caçador, desempenha um papel fundamental para a definição da condição humana.

Por meio dos relatos etnográficos referentes a diferentes populações ameríndias - Bororo, Toba, Wari', Kaxinawá, Yawalapíti, Krahó, Piro e Jodï -, pode-se observar as diferenças e semelhanças concernentes às noções de pessoa que compõem o vasto universo das cosmovisões indígenas. Note-se, portanto, que ao contrário das concepções ocidentais em que o social é reconhecido apenas sobre o 
corpo, por meio de ornamentação ou condicionamento à prática de exercícios, nas sociedades indígenas, o social é percebido no corpo como o meio para sua construção material. A corporalidade, enquanto principal idioma simbólico através do qual a noção de pessoa é expressa, denota que, nas cosmologias ameríndias, de modo geral, não se nasce pessoa, mas sim torna-se pessoa mediante as interações sociais. É o espaço social e as relações que o constituem que definem quem está ou não apto a receber o status de pessoa, e é justamente nesse espaço de tempo do tornar-se pessoa que se encontram os interditos de vida.

\section{Causas de interditos de vida}

Escassos são os registros na literatura antropológica sobre aquilo que entre os povos indígenas pode ser identificado como causas de interdito de vida para os recém-nascidos. Frente a isso, encontrei algumas citações pontuais que, conforme sugere Holanda (2008), podem ser classificadas em prescrições sociais que impossibilitam a formação de determinadas pessoas (caso de morte de neonatos gêmeos ou com debilidades físico-motoras), deliberações coletivas sobre determinadas situações (necessidade de pai legítimo e mãe para o reconhecimento da criança e inserção em uma rede de parentesco) e casos específicos, nos quais se avalia a viabilidade de deixar o recémnascido viver ou deixá-lo morrer.

Para o caso de parto gemelar, de acordo com Holanda (2008), o interdito de vida se aplica sob a justificativa mitológica que prescreve a impossibilidade de gêmeos diante do sagrado evocado pelos heróis fundadores da humanidade, ou seja, a gemeleidade evoca uma duplicidade que só cabe ao mito. Para Kensinger (apud SANTOSGRANERO, 2011), em decorrência da perspectiva indígena de que as mulheres podem ser fecundadas por animais, espíritos e outras pessoas não humanas, o nascimento de gêmeos é considerado uma manifestação dessa filiação monstruosa, daí a necessidade de destruir essa criança ao nascer.

Outra justificativa seria a dificuldade que cuidar de dois bebês ao 
mesmo tempo geraria para o núcleo familiar. Sob essa perspectiva, Granzberg sugere a hipótese de que "o infanticídio gemelar ocorre em sociedades que não oferecem condições suficientes para a mãe criar duas crianças de uma só vez, ao mesmo tempo em que deve cumprir outras responsabilidades" (GRANZBERG, 1973, p. 406). Assim, a chegada de gêmeos significaria um impedimento para a mãe realizar suas funções cotidianas. Nesse sentido, Granzberg (1973) compreende que, diante de um parto gemelar, existe a necessidade de se escolher entre a vida da criança ou a preservação da rede de reciprocidades que circunscreve a esfera social.

Baldus (1979) não fala especificamente sobre o interdito de vida de gêmeos, mas vê como explicação para essa prática exclusivamente causas econômicas. Afirma que, entre povos nômades, a mãe "[...] não pode, todos os anos, deixar com vida um filho, sem criar, graças a isso, um impedimento funesto para a alimentação conveniente de outro, nascido anteriormente" (BALDUS, 1979, p. 65). Entretanto, para o autor, entre os Bororo, por exemplo, a causa econômica aparece disfarçada pela crença que estabelece uma conexão entre a criança ainda não nascida com sonhos ruins de seus parentes, principalmente da mãe, durante a gestação. Tais sonhos seriam prenúncios de problemas para a aldeia, e a criança seria o causador, diante disso, o grupo decide pelo sacrifício desta logo após seu nascimento.

Já entre os Kaiabi, Pagliaro (2005) afirma que diante do caso de nascimento gemelar, o interdito de vida recaía sobre o bebê que nascesse por último, por acreditar-se que o mesmo era filho de outro pai. No entanto, atualmente, junto a esse povo observam-se gêmeos em idade adulta, o que pressupõe que tal prática tenha sido extinta.

No que se refere à elaboração corporal e nas expectativas sociais que advém da mesma, ocorre a total relação entre a autonomia pessoal e a habilidade de viver conjuntamente, daí o interdito de vida para recém-nascidos portadores de alguma debilidade físico-motora. É também sobre a corporalidade que recai um dos aspectos da negação do status de pessoa, como relata Carneiro da Cunha:

[...] seres disformes, isto é, que negavam as proporções do corpo humano, o que em outro código, vem a ser a mesma coisa: estranho à sociedade em um 
caso, à "humanidade" no outro, negando em seu próprio corpo a articulação harmoniosa das partes, eles eram sempre "os de fora", "o outro", os que negavam por sua própria existência a soberania de uma ordem (CARNEIRO DA CUNHA, 1978, p. 86).

Entre os Kamaiurá, Junqueira e Pagliaro (2009) também destacam a existência de interdito de vida para os recém-nascidos que apresentem má formação, cabeça com tamanho desproporcional ao corpo, ou feição de animal, bem como em casos de nascimento gemelar, ou de crianças geradas por mães solteiras, ou fora do casamento. Contudo, as autoras asseveram que atualmente tem sido registrada uma grande incidência de casos de crianças socialmente sem pai criadas por seus avós ou mesmo pela própria mãe.

Para os Kaxinawá, conforme Lagrou (apud SANTOS-GRANERO, 2011), crianças que nascem com anomalias e deformidades são consideradas filhas de espíritos, portanto são "crianças-espíritos" e devem ser sacrificadas logo após seu nascimento. Todavia, tanto o nascimento gemelar como de criança portadora de alguma deformidade física é também interpretado como quebra de tabus por um dos pais, o que representa uma ameaça à vida social.

Metatti (1992), por sua vez, embora não faça alusão à existência de interdito de vida para recém-nascidos portadores de deficiência física, afirma que, para os índios Matis, a corporalidade e as expectativas sociais que dela advêm ocupam uma dimensão central, constituindo a base somática sobre a qual as culturas pano se constroem.

Tais bases seriam os movimentos dos membros inferiores, a atividade sexual, os movimentos dos membros superiores e boca, aqui enumerados segundo a ordem em que parecem ganhar importância social ao longo do ciclo de vida (METATTI, 1992, p. 158).

Através das visitas do Mariwin, personagens rituais que visitam as malocas dos Matis, as crianças são estimuladas a andar desde a tenra idade, isso porque a capacidade de locomover-se:

Além de necessário à realização das atividades de subsistência, o ato de caminhar tem grande valor social em sociedades como a Marubo, que cultiva as 
constantes visitas, individuais ou coletivas, de maloca a maloca, os freqüentes convites para festas, quando os caminhos são especialmente limpos pelos anfitriões, e que se liga ao próprio mundo sobrenatural por vários caminhos (MONTAGNER apud MELATTI, 1992, p. 158159).

A partir da juventude, os Matis passam a praticar atividades sexuais tanto como forma proporcionadora de prazer como também associada à fecundidade. Os movimentos de braços e mãos são associados ao trabalho, e, assim como a capacidade de andar, são importantes desde a tenra idade, tendo seu valor social acentuado entre "[...] homens e mulheres casados, não só nos cuidados de manutenção da família, mas também na produção de alimentos e bebidas para festas e dos instrumentos para isso necessários [...]" (MELATTI, 1992, p. 159). A importância da boca e da sua funcionalidade na fala é igualmente importante desde a infância; entretanto, é apenas por volta dos trinta anos que um homem, já casado e com filhos, tem acesso ao uso do rapé e da ayhuasca, indispensáveis às atividades que fazem uso da linguagem ritual.

O acento dessa descrição de Melatti (1992) recai, portanto, sobre a importância atribuída pelos indígenas, de modo geral, à capacidade física de plena realização de atividades e obrigações sociais.

A negação da condição do status de pessoa do recém-nascido, conforme Holanda (2008), também ocorre quando há a ausência do pai legítimo, seja porque a mãe ainda não se casou ou está separada do marido, seja em casos de viuvez ou quando a gravidez ocorre em um período que o marido estava fora da aldeia. A importância da figura do pai justifica-se, em parte, pela crença de que a prática de relações sexuais durante a gestação contribui para a formação e o fortalecimento do feto (CONKILN e MORGAN, 1996; TOLA, 2007). Além disso, posteriormente ao nascimento, a figura do pai é importante para cumprir as obrigações da couvade, e também para fornecer alimento para a mãe e para a criança (AYTAI, 1979; BALDUS, 1979; TOLA, 2007). Ao mesmo tempo, a ausência do pai implicaria na falta de conexões sociais adequadas (SANTOS-GRANERO, 2011). Todavia, conforme mencionei acima, junto a alguns grupos indígenas, atualmente existe um número significativo de crianças sem pai social que são criadas por 
seus avós, ou então pela própria mãe (JUNQUEIRA e PAGLIARO, 2009).

Entre alguns povos há registros de casos em que o interdito de vida é pautado no critério de preferência pelo sexo masculino, como por exemplo, entre os Yanomani e os Juruna (PAGLIARO, 2005). Ainda de acordo com a autora, entre os Kaiabi, especula-se que o interdito de vida também recaía sobre recém-nascidos gerados por meio de relações extraconjugais, ou de violência sexual. Entre os Wari', Conklin e Morgan (1996) afirmam que o interdito de vida era prescrito apenas em uma situação: quando uma jovem solteira engravidasse e o pai biológico se recusasse a casar com ela, ou fosse impedido de fazê-lo por esta representar uma relação incestuosa. Contudo, posteriormente ao contato e intervenção de missionários e dos órgãos governamentais, o interdito de vida passou a ser uma decisão da mãe juntamente com seu grupo de parentesco, podendo, dessa forma, não ocorrer.

Temos então a descrição daquilo que, em tese, corresponde às causas de interditos de vida entre as sociedades indígenas. O tom descrente sobre sua veracidade não reside na desconfiança da seriedade desses relatos etnográficos, mas sim na atitude etnocêntrica da sociedade ocidental em compreender que as noções de vida, pessoa e humanidade repousam sob a égide do relativismo cultural. Não obstante, vale lembrar que essas descrições foram elaboradas a partir de narrativas históricas, o que implica na impossibilidade de tomá-las como verdade na vivência cotidiana desses povos. E para os poucos casos outrora noticiados, João Pacheco de Oliveira (2009) ressalta que:

Nas poucas ocasiões em que foram noticiados fatos que parecem indicar efetivamente o abandono ou a morte de crianças indígenas isto se dava como resposta a um infortúnio ou desgraça muito maior, que ameaçava atingir aquela pessoa, a sua família e a sua comunidade. A decisão jamais era tomada com leveza ou leviandade, implicando em sofrimento e tensão, mas vindo a ocorrer sempre com respeito, discussão e responsabilidade. Um paralelo em nossa sociedade seriam os conselhos de família, as juntas médicas e os tribunais (OLIVEIRA, 2009, p. 02).

O que eu quero acrescentar à pauta de reflexão, portanto, é que as negociações concernentes à gestão da família e ao cumprimento de obrigações sociais se fazem presentes em toda e qualquer sociedade, 
mudando apenas os moldes através dos quais tais práticas são social, moral e judicialmente aceitas. Ao mesmo tempo, a concepção ocidental de vida e pessoa, encarcerada nos princípios biológicos, se nega a aceitar outra lógica em que a vida e a pessoa são constituídas por meio de um complexo de relacionamentos sociais. Entretanto, como sugere Santos-Granero (2011), nas sociedades ocidentais tais conceitos também não são mais tão isomórficos quanto outrora. Tanto o início da vida, no caso de aborto, quanto o seu fim, no caso de eutanásia, estão já há algum tempo postos em xeque, o que evidencia claramente que a concepção de vida, de pessoa, e até mesmo de humanidade, são construtos culturais e, deste modo, mutáveis ao longo dos tempos.

\section{Considerações finais}

Como argumento central por parte dos parlamentares que se posicionam a favor da Lei Muwaji está a preocupação com a vida e o bem-estar das crianças indígenas. Contudo, é preciso esclarecer que a infância enquanto modo particular de pensar a criança muda de um contexto histórico, cultural e social para outro. Logo, a concepção ocidental de infância, que, por sua vez, norteia os discursos em torno desse projeto de lei, não cabe, propriamente, para analisar a relação entre os indígenas e suas crianças.

Segundo Mandulão, apesar da grande diversidade cultural entre os povos indígenas, a forma de tratar as crianças é semelhante:

Quando a criança nasce, é uma extensão da mãe que a amamenta e a protege. A criança é socializada pela família e nas relações cotidianas da aldeia. Ela aprende fazendo, experimentando, imitando os adultos. As crianças acompanham os pais e os seus brinquedos são miniaturas dos instrumentos que posteriormente irão utilizar em sua vida de adulto. Neste sentido, podemos inferir que a forma de ensinar nas comunidades indígenas tem como princípios inseparáveis a construção do ser, pela observação, pelo fazer, testado dentro de um contexto real (MANDULÃO apud ZOIA e PERIPOLLI, 2010, p. 12).

Zoia e Peripolli (2010) também afirmam que as crianças indígenas 
são tratadas com grande liberdade. Podem circular livremente por todos os espaços da aldeia e relacionar-se com todos os membros da comunidade, o que implica numa maior compreensão da teia de relações em que estão inseridas. Esse contato com a comunidade como um todo possibilita às crianças indígenas que o aprendizado ocorra em todos os momentos. Sob o princípio de que todos educam todos, cada membro da comunidade é um agente educador.

Tassinari corrobora dizendo que:

[...] Ao contrário de nossa prática social que exclui as crianças das esferas decisórias, as crianças indígenas são elementos-chave na socialização e na interação de grupos sociais e os adultos reconhecem nelas potencialidades que as permitem ocupar espaços de sujeitos plenos e produtores de sociabilidade (TASSINARI, 2007, p. 23).

Inúmeros são os relatos etnográficos que retratam o valor positivo atribuído às crianças indígenas no interior de suas sociedades. Entre os Karajá, por exemplo, conforme Aytai (1979), após o nascimento do primeiro filho, o homem passa a ser identificado como o "pai de fulano". Em casos de separação dos cônjuges, sempre há disputa acerca de quem ficará com os filhos. E em casos de esterilidade conjugal, ao invés da separação, o casal opta pela adoção de crianças, geralmente órfãs. Deste modo:

Não encontramos crianças semi-abandonadas: na falta dos pais, as criancinhas são imediatamente adotadas por outras famílias. As crianças adotadas são consideradas próprias, não são mais devolvidas, e as obrigações e proibições oriundas do parentesco/ por exemplo, a proibição do incesto/ aplicam-se nelas com todo rigor (AYTAI, 1979, p. 02).

Além disso, o autor afirma que as mulheres, durante a amamentação, fazem uso de ervas que aumentam a produção de leite, e, em alguns casos, as meninas com idade entre 12 e 14 anos também fazem uso desses recursos para assim produzirem leite e ajudarem na amamentação das crianças.

Os indígenas têm grande preocupação com o bem-estar físico e moral de suas crianças, tanto que as famílias dedicam-se intensamente 
à sua educação, acompanhando-as em todas as fases de crescimento. Como é o caso dos Yanomani, em que, as mulheres, após cumprirem os ritos pós-parto e depois da queda do cordão umbilical, retornam à sua vida ordinária, sem, no entanto, se separarem do bebê. Este é levado preso ao corpo da mãe até que a criança se torne autônoma (COCCO apud HOLANDA, 2008).

Nota-se, então, que as crianças indígenas, assim como as crianças de nossa sociedade, recebem cuidados e atenções especiais. Nesse cenário, como salienta Oliveira (2009), o abandono ou morte de crianças ocorria apenas como resposta a um infortúnio ou desgraça maior que ameaçava atingir aquela pessoa, sua família e sua comunidade.

Para os indígenas, a família é um projeto consciente; dessa forma, é comum a presença de estratégias reprodutivas marcadas por algum tipo de controle de natalidade. Existem casos, como demonstra Aytai (1979), entre os Karajás, que as mulheres evitam ter mais filhos, se já têm uma prole extensa, ou se o marido é um caçador/pescador ineficiente, ou viciado em bebida, dentre outros motivos. Entre os Asuriní do Xingu, os filhos em uma família nuclear não devem exceder o número de dois indivíduos (MÜLLER, 1984/1985). Os métodos contraceptivos, de modo geral, pautam-se na utilização de ervas, ou então, no prolongamento do período de amamentação (AYTAI, 1979).

Roberto Cardoso de Oliveira (1959), em seu estudo sobre os Tapirapé, também indica a ocorrência de mecanismos de controle populacional. Entre esse povo, um casal não poderia ter mais de três filhos. Para o autor, essa estratégia estaria diretamente relacionada com a expulsão dos Tapirapé de suas terras tradicionais e com as adaptações advindas do processo de deslocamento:

[...] como se sabe, os Tapirapé para manterem uma estrutura demográfica que os permitisse conservar um tipo de população especialmente ajustada ao seu antigo meio-ambiente (compreendendo aí o habitat e a tradicional tecnologia com a conseqüente trama de relações sociais), teriam instituído o infanticídio do quarto filho em diante, i. e., um casal não poderia ter mais de 3 (número ideal, demograficamente falando, para renovar a população sem incrementá-la) (OLIVEIRA, 1959, p. 10). 
Portanto, se pensarmos sob a perspectiva da recorrência de estratégias de controle populacional, percebemos que as mesmas ocorrem em todas as sociedades, variando apenas as formas como se inscrevem nos discursos social e moralmente aceitos. Perpassando diretamente esses discursos estão os valores da cosmologia ocidental moderna, alicerçados na oposição das províncias ontológicas Natureza e Cultura, que os constituem e influenciam diretamente na determinação da fronteira entre o humano e o não humano. Nesse sentido, aquilo que se convencionou chamar de infanticídio indígena, nada mais é que "estratégias reprodutivas que dizem respeito ao processo de fabricação humana, negando e afirmando parentes" (HOLANDA, 2008, p. 63).

Entretanto, ao tratarmos desse assunto, devemos ter em mente, como adverte João Pacheco de Oliveira, que:

[...] práticas de infanticídio entre os indígenas são virtualmente inexistentes no Brasil atual, como logo vieram a esclarecer a FUNAI e os antropólogos. São raros os casos onde exista informação etnográfica confiável ou consistente sobre tais fatos (OLIVEIRA, 2009, p. 01).

Da mesma forma, Holanda (2008) também denuncia a escassez de dados diretos sobre taxas de mortalidade nos estudos populacionais de povos indígenas. Segundo a autora, mesmo quando se tem em mãos tais dados, deve-se levantar o questionamento de que:

se no número de crianças "mortas" estão inclusos os
interditos de vida, se os natimortos efetivamente
nasceram sem vida e o que quer dizer a presença
constante de "outras causas mortis" neste tipo de
estudo (HOLANDA, 2008, p. 63).

Além disso, onde estão os corpos das 300 crianças mortas por ano, vítimas de infanticídio indígena de que falam os representantes do Legislativo? Se contarmos apenas os 06 anos de duração desse debate na Câmara dos Deputados, já teríamos um total de 1.800 corpos. Mas onde estão esses corpos de que ninguém fala e ninguém vê? Isso denota a inexistência de qualquer preocupação com a factualidade.

Frente $\mathrm{a}$ isso, precisamos refletir sobre a criminalização do infanticídio indígena a partir das configurações do cenário político- 
social atual, no qual essa prática constituiu-se mais como uma espécie de mito que propriamente como realidade. Nesse contexto, não podemos perder de vista os interesses e conflitos que cercam os indígenas e suas terras.

O debate sobre infanticídio indígena, na verdade, não traz nada de novo, apenas reafirma, porém agora sob a égide dos direitos humanos universais, as antigas acusações de selvageria, crueldade e irracionalidade dos indígenas. $O$ que temos agora não passa de um novo motivo, um novo pretexto para negarmos aos indígenas o que lhe é assegurado por direito - sua organização social, costumes, línguas, crenças, tradições e terras. Por conta de suas culturas primitivas, com práticas cruéis, eles abandonam, enterram, matam suas pobres crianças. Diante disso, como explicar o abandono de crianças em latas de lixo em nossa tão civilizada cultura?

Deste modo, o infanticídio indígena, quando acionado pelo discurso pautado nesse falso humanismo, ao invés de atribuir humanidade aos indígenas, faz é questioná-la e negá-la, o que se configura, portanto, no uso estratégico dos direitos humanos em prol de causas omissas. Causas omissas, sim, porque afinal de contas, como indaga Segato, "quem saberia a razão dos legisladores para insistir numa lei que criminaliza povos indígenas e torna mais distante seu acesso ao direito próprio e à sua própria jurisdição para solução de conflitos?" (SEGATO, 2007, p. 58).

Sob essa mesma lógica humanitária, inscreve-se também a Proposta de emenda à Constituição (PEC) 303/2008 de autoria do deputado Pompeo de Mattos (PDT/RS), que propõe a alteração do art. 231 da Constituição Federal para:

Art. 231. São reconhecidos aos índios, respeitada a inviolabilidade do direito à vida nos termos do art. $5^{\circ}$ desta Constituição, sua organização social, costumes, línguas, crenças e tradições, e os direitos originários sobre as terras que tradicionalmente ocupam, competindo à União demarcá-las, proteger e fazer respeitar todos os seus bens (MATTOS, 2008, p. 01).

Tanto a Lei Muwaji como a PEC 303/08 são exemplos do discurso civilizador-etnocêntrico sustentando por um falso humanismo, que 
encontra na retórica da lei o seu principal instrumento. Trazer à tona, ou até mesmo criar questões tão polêmicas sobre os indígenas e impregná-las no imaginário popular por meio de veículos de comunicação de massa, nada mais é que uma estratégia para justificar a expropriação de suas terras e de suas vidas. O interesse em legislar sobre a ocorrência de interditos de vida entre os indígenas, sobre a forma como esse povo determina suas fronteiras ontológicas, é apenas uma reedição dos moldes de dominação existentes há mais de 500 anos, é apenas a manutenção contínua do projeto colonial. Sob essa perspectiva, o infanticídio indígena corresponde a uma alegoria política e jurídica, que encontra sua principal base de argumentação na Declaração Universal dos Direitos Humanos, e que, imbricado em relações de poder, caminha no sentido da negação da racionalidade e da diferença cultural das populações indígenas brasileiras, dessa forma, criando manobras que legitimem a intervenção do Estado, reafirmando, assim, o poder tutelar, que, na prática, não foi completamente sepultado.

\section{Referências bibliográficas}

AYTAI, Desidério. Obstetrícia Karajá: segunda parte. Publicações do Museu Histórico de Paulínia, São Paulo, n. 10, p. 1 -11, 1979.

BALDUS, Herbert. Ensaios de etnologia brasileira. São Paulo: Companhia Editora Nacional, 1979.

CÂMARA DOS DEPUTADOS. Audiência Pública: esclarecimento sobre denúncia de retirada não autorizada de crianças de aldeia indígena. Comissão da Amazônia, Integração Nacional e Desenvolvimento Regional. Brasília, Departamento de Taquigrafia, Revisão e Redação. 2005.

Audiência Pública: debate sobre infanticídio em áreas indígenas. Comissão de Direitos Humanos e Minorias. Brasília, Departamento de Taquigrafia, Revisão e Redação. 2007.

CARNEIRO DA CUNHA, Manuela. Os mortos e os outros: uma análise do sistema funerário e da noção de pessoa entre os índios Krahô. São Paulo: Hucitec, 1978. 
De amigos formais e pessoa: de companheiros, espelhos e identidades. Boletim do Museu Nacional, Rio de Janeiro, n. 32, p. 31-39, 1979.

CONKLIN, Beth; MORGAN, Lynn. Babies, Bodies and the Production of Personhood in North America and Native Amazonian Society. Ethos, Ojeda, v. 24, n. 4, p. 657-694, 1996.

DAMATTA, Roberto. Carnavais, malandros e heróis: para uma sociologia do dilema brasileiro. Rio de Janeiro: Rocco, 1997.

DUMNT, Louis. Ensaios sobre o individualismo: uma perspectiva antropológica sobre a ideologia moderna. Lisboa: Dom Quixote, 1992a.

. Homo Hierarchicus: o sistema de castas e suas implicações. São Paulo: EdUSP, 1992b.

GRANZBERG, Gary. Twin Infanticide: a cross-Cultural Testo of a Materialist Explanation. Ethos, Ojeda, v. 1, n. 4, p. 405-412, 1973.

HOLANDA, Marianna Assunção Figueiredo. Quem são os humanos dos direitos?: sobre a criminalização do infanticídio indígena. 2008. 157 f. Dissertação (Mestrado em Antropologia Social) - PPGAS/UnB, [2008].

JUNQUEIRA, Carmem; PAGLIARO, Heloisa. O saber Kamaiurá sobre a saúde do corpo. Caderno CRH, Salvador, v. 22, n. 57, p. 451-461, 2009.

LÓPEZ, Egleé. Noções de corporalidade e pessoa entre os Jodï. Mana, Rio de Janeiro, v. 12, n. 2, p. 359-388, 2006.

MATTOS, Pompeo de. Proposta de Ementa à Constituição no 303 de 2008. 2008. Disponível em: http://www.camara.gov.br/proposicoesWeb/prop_mostrarintegra;jsessionid=52E6EF4F 4E443AEF201862D654971F14.proposicoesWeb1 ?codteor=612809\&filename=Tramita cao-PEC+303/2008. Acesso em: 16 jun. 2014.

MAUSS, Marcel. Sociologia e Antropologia. São Paulo: Cosac e Naify, 1973.

Uma categoria do espírito humano: a noção de pessoa, a de "eu". In:

Sociologia e Antropologia. São Paulo: Cosac e Naify, 2003. p. 367- 397.

MELATTI, Julio Cezar. Enigmas do corpo e soluções dos Panos. In: CARDOSO DE OLIVEIRA, Roberto. Homenagem. Campinas: IFCH/UNICAMP, 1992. p. 143-166.

MCCALLUM, Cecilia. Morte e pessoa entre os Kaxinawá. Mana, Rio de Janeiro, v. 2, n. 2, p. 49-84, 1996.

MONCORVO FILHO, A. Histórico da proteção à infância no Brasil: (1500-1922). 
Rio de Janeiro: Departamento da Criança no Brasil, 1926.

MÜLLER, Regina Aparecida Polo. Asurini do Xingu. Revista de Antropologia, São Paulo, v. 27/28, p. 91-114, 1984/1985.

OLIVEIRA, João Pacheco de. Infanticídio entre populações indígenas: campanha humanitária ou renovação do preconceito? 2009. Disponível em: http://www.abant.org.br. Acesso em: 12 nov. 2011.

OLIVEIRA, Roberto Cardoso de. A situação atual dos tapirapé. Boletim do Museu Paraense Emílio Goeldi, Belém, v. 3, p. 11, 1959.

OPAS, Minna. Mutually Exclusive Relationships: corporeality and differentiation of persons in Yine (Piro) social cosmos. Journal of the Society for the Anthropology of Lowland South America, v. 3, n. 2, n. p. 2005. Disponível em: http://digitalcommons.trinity.edu/tipiti/vol3/iss2/2 . Acesso em: 28 jun. 2014.

PAGLIARO, Heloisa; AZEVEDO, Marta Maria; SANTOS, Ricardo Ventura (Org.). Demografia dos povos indígenas do Brasil. Rio de Janeiro: Editora FIOCRUZ, 2005.

SANTOS-GRANERO, Fernando. Hakani e a campanha contra o infanticídio indígena: percepções contrastantes de humanidade e pessoa na Amazônia brasileira. Mana, Rio de Janeiro, v. 17, n. 1, p. 131-159, 2011.

SEEGER, Anthony; DAMATTA, Roberto; VIVEIROS DE CASTRO, Eduardo. A construção da pessoa nas sociedades indígenas brasileiras. Boletim do Museu Nacional, Rio de Janeiro, n. 32, p. 2-19, 1979.

SEGATO, Rita. Audiência Pública: debate sobre infanticídio em áreas indígenas. Comissão de Direitos Humanos e Minorias. Brasília, Departamento de Taquigrafia, Revisão e Redação. 2007.

TASSINARI, Antonella. Concepções Indígenas de Infância no Brasil. Tellus, Campo Grande, v. 7, n. 13, p. 11-25, 2007.

TOLA, Florencia. "Eu não estou só(mente) em meu corpo": a pessoa e o corpo entre os Toba (Qom) do Chaco argentino. Mana, Rio de Janeiro, v. 13, n. 2, p. 499-519, 2007.

VIERTLER, Renate Brigitte. O estudo de parentesco e as práticas de nominação entre os índios Borôro, os nomes de caça pela morte de um Borôro (Iebio-mage). Revista de Antropologia, São Paulo, v. 21, p. 61-68, 1978.

A noção de pessoa entre os Bororo. Boletim do Museu Nacional, Rio de Janeiro, v. 32, p. 20-30, 1979.

VIVEIROS DE CASTRO, Eduardo B. A fabricação do corpo na sociedade xinguana. Boletim do Museu Nacional, Rio de Janeiro, n. 32, p. 40-49, 1979. 
ZOIA, Alceu; PERIPOLLI, Odimar J. Infância indígena e outras infâncias. Espaço Ameríndio, Porto Alegre, v. 4, n. 2, p. 9-24, jul./dez. 2010. 